\title{
RECEPCIÓN CLÁSICA EN LA ESCRITURA PERIODÍSTICA Y POLITIICA CHILENA A COMIENZOS DE LA GUERRA DEL PACÍFICO (1879): SOBRE HÉROES, GESTAS Y DICTADURAS
}

\author{
CLASSIC RECEPTION IN CHILEAN JOURNALISM AND POLITICAL \\ WRITING AT THE BEGINNING OF THE WAR OF THE PACIFIC \\ (1879): ON HEROES, DEEDS AND DICTATORSHIPS
}

\section{MARÍA GABRIELA HUIDOBRO SALAZAR*, GONZALO SERRANO DEL POZO**}

Resumen: El artículo revisa, desde el enfoque de los estudios de recepción clásica, la mención de motivos y elementos de la tradición clásica en algunos textos chilenos de opinión pública escritos a mediados de 1879, a propósito de los acontecimientos de la Guerra del Pacífico. El análisis rescata dos líneas discursivas, una laudatoria y una crítica, para proponer que el uso de la tradición clásica revela una imagen idealizada del mundo antiguo, que sirvió para fortalecer el significado de los argumentos expuestos.

Palabras clave: Recepción clásica, Guerra del Pacífico, opinión pública, heroísmo, dictadura romana.

Aвstract: Within the framework of classical reception studies, this article studies the references to motifs and elements of the classical tradition in a corpus of Chilean public-opinion essays about the War of the Pacific written in mid-1879. The analysis highlights two discursive threads, one laudatory and one critical, in order to demonstrate how the use of the classical tradition reveals an idealized image of the ancient world, which served to strengthen the meaning of the arguments presented.

Keywords: Classical reception, War of the Pacific, public opinion, heroism, Roman dictatorship.

Recibido: 22.05.2019. Aceptado: 01.04.2020.

* Doctora en Historia. Universidad Andrés Bello, Santiago, Chile. Correo electrónico: mhuidobro@unab.cl. Orcid: http://orcid.org/0000-0001-9980-6175.

** Doctor en Historia. Universidad Adolfo Ibáñez, Santiago, Chile. Correo electrónico: gserrano@ uai.cl. Orcid: https://orcid.org/0000-0002-9875-7241. 


\section{INTRODUCCIÓN}

A $\begin{aligned} & \text { mediados de } 1879 \text { circuló en Valparaíso -y quizás en Santiago- un } \\ & \text { pasquín anónimo de siete páginas, titulado La Patria está en Peligro }\end{aligned}$ $(1879)^{1}$. Se trataba de un documento que, con tono alarmista, criticaba al gobierno chileno del presidente Aníbal Pinto en el contexto de los primeros meses de la Guerra del Pacífico, conflicto que, entre 1879 y 1884, enfrentó a Chile contra Bolivia y Perú.

El pasquín advertía que la indeterminación de las autoridades chilenas llevaría al país a perder la guerra. Por eso, su autor no solo realizaba una crítica, sino que proponía suspender la presidencia de Pinto, para reemplazarla por una dictadura que imitase al sistema de Roma antigua.

En este sentido, el documento resulta interesante desde la perspectiva de los estudios de recepción, pues da cuenta del conocimiento y admiración, por parte del autor, de un modelo distante, temporal y espacialmente, de su realidad -el de la república romana antigua-, al que, sin embargo, consideraba como una opción válida para su reimplementación en Chile a fines del siglo XIX.

La fuente ofrece un ejemplo de recepción cultural de la tradición clásica, a través del cual una idea de la cultura política del mundo antiguo se constituyó en objeto de actualización. No se trata de un caso aislado: la prensa de la época ofreció un espacio de debate y opinión pública sobre los acontecimientos diarios de la Guerra del Pacífico, en cuyos textos se advierte constantemente la mención de ideas, personajes y tópicos del mundo antiguo grecorromano.

Entre los autores de estos textos se cuentan políticos, diplomáticos, escritores y publicistas. Se trataba, por tanto, de ciudadanos letrados, miembros de una élite, formados en un mismo contexto cultural y educativo, en el que los imaginarios sobre la Antigüedad clásica eran comprendidos y

\footnotetext{
${ }^{1}$ En el catálogo de la Biblioteca Nacional de Chile, el texto aparece atribuido a Benjamín Vicuña Mackenna. Sin embargo, el pasquín no figura en su catálogo de publicaciones ni coincide con las ideas de este autor que, a inicios de 1879, era senador de la República. Vicuña Mackenna fue un activo promotor de la guerra, pero, también, un defensor del poder legislativo para influir sobre el poder ejecutivo en la conducción de este conflicto, por lo que resultaría extraño que promoviese una dictadura. Los pasquines, escritos generalmente anónimos de contenido satírico o crítico, fueron recursos comunes en la cultura sociopolítica hispanoamericana desde tiempos coloniales, para instalar debates, abriendo espacios de opinión pública y sociabilidad que permiten conocer perspectivas diversas sobre las discusiones políticas de su tiempo (Guerra, 2002, pp. 357-384; Castillo y Amelang, 2010).
} 
compartidos, lo que pudo permitirles dialogar desde códigos y claves conceptuales comunes. En este sentido, se trata de una comunidad de interpretación, cuyos discursos pueden abordarse atendiendo al contexto cultural en el que se formaron y al contexto político que los inspiró (Chartier, 1996, p. 40).

Sobre esta consideración, es posible plantear, como hipótesis, que el uso de la tradición clásica en esta escritura periodística y política chilena, en el marco de la Guerra del Pacífico, puede entenderse como un recurso argumentativo de carácter político y axiológico para el fortalecimiento o legitimación de las ideas y opiniones expresadas en la prensa de la época. La revisión documental evidencia ciertas líneas discursivas y argumentativas constantes que podrían permitir, por una parte, conocer el imaginario sobre la Antigüedad Clásica en la sociedad letrada chilena de fines del siglo XIX y, por otra, fortalecer la interpretación del sentido discursivo de los textos de opinión pública chilena a mediados de 1879, en relación con los temores, motivos de admiración, críticas y expectativas sobre la guerra que recién comenzaba.

Los discursos registrados en la prensa, aunque se nutrieron principalmente del republicanismo constitucional y de la tradición ideológica de la independencia (Mc Evoy 2011, p. 411), encuentran sus antecedentes indirectos en la tradición clásica de la que estos discursos eran herederos.

Para abordar las fuentes con esta perspectiva, se comenzará por revisar el contexto cultural que habría permitido a la sociedad letrada chilena conocer la historia antigua de Grecia y Roma y acceder a la lectura de sus principales autores. Asimismo, la revisión contemplará los antecedentes de la Guerra del Pacífico en los primeros meses de 1879, como el contexto político que inspiró la redacción de los documentos a estudiar. De esta manera, será posible, luego, realizar un análisis de los textos que evidencian la presencia de la tradición clásica, para inferir las líneas argumentativas que subyacen y poner así en valor el rol que los modelos e imaginarios sobre el mundo clásico ejercieron en los discursos periodísticos y políticos sobre la Guerra del Pacífico en sus primeros meses de desarrollo.

Los estudios de recepción clásica permiten abordar, en este sentido, un conflicto que, aunque extensamente investigado, solo recientemente ha sido estudiado desde líneas que trascienden lo estrictamente político, diplomático y militar. La propuesta espera contribuir así a complementar los análisis culturales e intelectuales que existen sobre la Guerra. 


\section{LOS CLÁSICOS EN EL CONTEXTO CULTURAL CHILENO DEL SIGLO XIX}

La enseñanza del latín y la lectura de obras antiguas, especialmente romanas, en Chile, fueron parte del itinerario educativo y de los círculos culturales de los sectores sociales de élite a lo largo del siglo XIX. Desde tiempos coloniales, el canon de lectura escolar y universitaria consideraba algunas obras clásicas, especialmente para la formación en retórica, gramática y filosofía moral. Cicerón, Ovidio, Virgilio, Horacio, Aristóteles y Catón, entre otros, fueron autores de lectura ineludible. Así lo demuestran los prospectos universitarios e inventarios de libros y bibliotecas del siglo XVIII (Huidobro, 2017).

La ruptura con el orden colonial y la instalación de un gobierno republicano en Chile, a comienzos del siglo XIX, no supusieron mayores cambios en los currículos educacionales. Si bien los objetivos diferían, pues desde entonces se aspiraría a formar ciudadanos para la república, la educación humanista mantuvo un lugar de primera relevancia, siguiendo los preceptos que dominaban en el sistema educacional europeo. Para eso, se introdujeron, hacia mediados de siglo XIX, diversos manuales de enseñanza de Historia Antigua, sobre todo compendios de Historia de Grecia y de Roma, que propiciaban la exaltación de valores políticos y patrióticos (Villalobos, 2017, pp. 17-19; Guerrero, 2010, pp. 115-118). Después de todo, las Humanidades Clásicas se cultivaban no solo para el aprendizaje de la lengua y la literatura griega y latina, sino para formar, mediante su ejemplo histórico, un espíritu republicano, sentido crítico, juicio moral y la capacidad de discernimiento estético y ético, otorgando estatus a quienes se formaban en ellas, especialmente en latín. Aunque no todos dominaran esta lengua y muchos solo conocieran algunas citas, alocuciones o autores, el prestigio simbólico del latín ofrecía un vínculo de adhesión y una garantía de reconocimiento a la comunidad cultural de la élite (Hurtado, 2012, p. 31) ${ }^{2}$.

En este sentido, como afirma Poblete (2002, p. 212), el latín -y la cultura clasicista- operó como un dispositivo educativo para la formación de subjetividades en el espacio social chileno del siglo XIX, como parte de la gubernamentalidad que organizaba a la república. Hacia 1854, período de juventud para algunos autores de los textos periodísticos y políticos sobre la Guerra del Pacífico, el latín era, después del francés, la lengua más ense-

\footnotetext{
${ }^{2}$ El griego fue cultivado en menor medida. No obstante, en 1844 se oficializó una primera cátedra, a cargo del helenista Louis Antoine Veldel-Heyl (Villalobos, 2008, p. 27).
} 
ñada y estudiada en Chile, lo que permitía, mediante la lectura de citas y obras clásicas, un acceso al conocimiento de la historia antigua (Subercaseaux, 1997, p. 261).

El Plan de Estudios Humanistas, apoyado por Ignacio Domeyko, Antonio Varas y Andrés Bello en 1843, había impulsado esta tendencia para la enseñanza secundaria, reforzada por el Plan de Estudios del Instituto Nacional de 1875 y la decisión de la Universidad de Chile, en 1865, de mantener la obligatoriedad del latín para los estudiantes de Bachiller en Humanidades, Leyes y Medicina ${ }^{3}$.

Los registros de impresión y circulación de libros también dan cuenta de la vigencia que tenía el aprendizaje de la historia antigua grecorromana. Como señala Subercaseux (1993, p. 67), entre 1840 y 1880, se gestó un impulso a la industria librera en Chile, que pudo fortalecer la preparación intelectual y cultural de la élite, en el marco de lo cual hubo espacio para la publicación y acceso de obras relativas al mundo clásico. Entre ellas, Ramón Briseño (1965) registra los textos Historia griega, Historia antigua e Historia romana, de M. Lamé Fleury, impresos en 1843 y 1845 para el Instituto Nacional; e Historia antigua, griega i de la Edad-Media, de Víctor Boreau, traducido por Raimundo Silva y Miguel Luis Amunátegui para el Instituto Nacional en 1853. De acuerdo a los mismos registros de Briseño (1965), el Compendio de historia antigua, el de Historia griega y de Historia romana de Víctor Duruy fueron traducidos y aprobados para su enseñanza en Chile en 1863 y 1872. El Compendio de historia antigua de M. Lesieur fue traducido en 1867 para su uso en la Escuela Militar y el Compendio de Historia griega de Drioux fue traducido y publicado en 1872. El Pequeño Plutarco de José Bernardo Suárez fue publicado en Santiago en 1871, el Compendio de historia antigua i griega de Chantrel fue impreso en 1873 y la Historia antigua de L. Fleury fue publicada en Valparaíso entre 1869 y 1872. La Gramática latina de Francisco Bello fue también objeto de reediciones, siendo publicada en 1861 y 1876.

Del mismo modo, en 1867, 1871 y 1875, se imprimió y reeditó la obra Elementos de literatura (Retórica y poética) de Diego Barros Arana, para ser utilizada como manual de enseñanza, basada en ediciones francesas de la

\footnotetext{
${ }^{3}$ De ello derivó, en 1866, la publicación de un documento sobre Latín i griego (Editorial Correo, Santiago) para enseñar estos idiomas en los colegios del Estado. Solo hacia 1876, se eliminó la obligatoriedad del latín, desapareciendo de los planes de estudio en 1880, pero en el período formativo de los autores a considerar para este análisis, la vigencia de su enseñanza tenía pleno vigor (Cruz, 2002, pp. 68-69; Serrano, 1994, pp. 157-158; Labarca, 1939, pp. 155-156; Idioma Latino. Sesión del 24 de mayo. Anales de la Universidad de Chile, t.27, 1865, pp. 35-77).
} 
Retórica de Aristóteles, la traducción castellana de las Instituciones oratorias de Quintiliano y los tratados latinos de Cicerón.

Si bien, en esos años, no se registran ediciones nuevas o locales de obras clásicas, estas sí formaban parte de las lecturas contenidas en los programas educativos. La publicación de textos alusivos al mundo grecorromano reafirma, además, las posibilidades de acceso al conocimiento de la cultura clásica que tuvieron los integrantes del círculo letrado chileno de la segunda mitad del siglo XIX, lo que pudo permitirles formarse un imaginario político y moral idealizado de los antiguos. Desde esa óptica es que pudieron valorar, en parte, los acontecimientos de 1879, ofreciendo, en su producción escrita, la representación de sus ideales, valores y temores desde las categorías históricas ofrecidas por la tradición clásica.

\section{LOS PRIMEROS MESES DE LA GUERRA DEL PACÍFICO}

Tras su emancipación del imperio colonial español, a principios del siglo XIX, Chile y Bolivia sobrellevaron, a lo largo de dicha centuria, numerosos desencuentros dados por la necesidad de definir y convenir sus límites territoriales. La situación se volvió especialmente compleja cuando se inició, de manera decidida, la explotación minera de guano y salitre en el desierto de Atacama, productos, para entonces, sumamente cotizados en Europa en el contexto de la revolución industrial.

Al comienzo, las disputas territoriales se zanjaron a través de tratados firmados en 1866 y 1874, pero estos no resultaron definitivos ni del todo satisfactorios para las partes involucradas. Por este motivo, Bolivia firmó un pacto secreto de alianza defensiva con Perú, en 1873, previendo una posible guerra con Chile ${ }^{4}$.

El tratado firmado por Bolivia y Chile en 1874 fijaba como límite el paralelo 24 y aseguraba que el gobierno boliviano no podía aumentar los impuestos durante 25 años a las compañías salitreras ubicadas entre los paralelos 23 y 24 . No obstante, en febrero de 1878, el gobierno boliviano determinó aumentar las cargas impositivas. Por este motivo, la Compañía de Salitre y Ferrocarril de Antofagasta, de capitales británicos y chilenos, solicitó el apoyo al gobierno chileno, quien realizó los reclamos respectivos, sin obtener respuesta de Bolivia.

\footnotetext{
${ }^{4}$ Aunque Perú no tenía conflictos territoriales con Chile, su economía, basada en la exportación de guano, había decaído a raíz del desarrollo del salitre.
} 
Frente a ello, fracasada una solicitud de arbitraje y en respuesta al inminente remate de la Compañía de Salitres y Ferrocarril de Antofagasta, el 14 de febrero de 1879, el ejército chileno desembarcó en el puerto boliviano de Antofagasta.

En reacción a esta ocupación, Bolivia declaró oficialmente la guerra a Chile. Perú, en tanto, se mantuvo neutral, hasta que Chile declaró la guerra a ambos países, iniciando un extenso conflicto (1879-1884) que tendría consecuencias permanentes en las relaciones de dichos Estados.

Para entonces, los tres países eran repúblicas democráticas. Más allá de las falencias del sistema y su verdadero carácter representativo, su institucionalidad funcionaba según un orden constitucional. En particular, la élite política chilena tenía una alta consideración de su estabilidad. Hacia 1879, Chile podía vanagloriarse de mantener una constitución desde 1833 y un régimen presidencial que no había sufrido alteraciones desde 1831 . El no haber sido derrotado en dos guerras de carácter internacional, como sucedió en 1836, contra la Confederación Perú-boliviana, y en 1866, contra España, era prueba de la estabilidad del sistema republicano.

La Guerra del Pacífico, desde sus inicios, contó con un amplio apoyo de la población chilena, tal como puede evidenciarse en la prensa de la época ${ }^{5}$. No obstante, el respaldo y las voces unísonas en favor de la guerra y del gobierno comenzarían a alterarse con el correr de los meses, debilitándose el apoyo al gobierno por la ausencia de un plan claro para obtener la victoria y por las erráticas acciones emprendidas, fruto de las diferencias de opinión y desencuentros entre los ministros, el Presidente y los jefes militares (Bulnes, 1911, pp. 122-152).

El 5 de abril de 1879, a iniciativa del almirante Williams Rebolledo, los chilenos iniciaron un bloqueo al puerto de Iquique. Sin embargo, a inicios de mayo, sin mayores novedades, y luego de tres meses de efectuada la ocupación de Antofagasta, la opinión pública comenzó a impacientarse. Frente a este panorama, Rebolledo decidió marchar al norte para enfrentarse a la escuadra peruana en Callao, sin tener conocimiento de que los principales buques peruanos, Huáscar e Independencia, iban rumbo al sur para liberar Iquique. Este puerto había quedado custodiado por la Esmeralda y la Covadonga, dos embarcaciones chilenas que no estaban en condiciones de oponer resistencia a la armada peruana.

\footnotetext{
${ }^{5}$ En el contexto de la guerra, la venta de diarios y pasquines aumentó significativamente, alcanzándose cerca de 178 periódicos publicados durante el periodo del conflicto (Castagneto, 2015, p. 18).
} 
Pese a eso, y frente al inminente ataque, la orden del capitán chileno, Arturo Prat, comandante de la Esmeralda, fue resistir hasta las últimas consecuencias. Y así ocurrió: Prat murió en un intento de abordaje al Huáscar, mientras su buque se hundió sin arriar su bandera. La Covadonga, en tanto, comandada por Carlos Condell, emprendió la retirada. En esta fuga, consiguió que la Independencia encallase en la costa.

La muerte del comandante Prat y el hundimiento de la Esmeralda calaron hondo en la población chilena (Sater, 2005). Sin embargo, aunque la causa de la guerra se volvió más popular (Vial, 1995), el sacrificio de Prat fue juzgado como el resultado de un error del Gobierno. El Huáscar se transformó en un temible enemigo en aguas chilenas, cuyas correrías generaron inquietud en la opinión pública, que exigía una acción decidida por parte de las autoridades.

Así, tras el combate naval de Iquique, surgieron en la opinión pública escrita chilena, dos líneas discursivas en torno al tema. La primera, ordenada por una retórica laudatoria, se orientó a glorificar a los héroes de Iquique, cuya gesta merecería inscribirse en la memoria de las grandes hazañas de la historia occidental. La segunda, por el contrario, inició un duro cuestionamiento a la forma de dirigir la guerra por parte del gobierno de Aníbal Pinto, sugiriendo alternativas para acabar con un liderazgo indeciso y conseguir, de este modo, la victoria en la guerra ${ }^{6}$.

Si bien dicotómicas en su tono y diferentes en su intención y objeto narrativo, en ambas líneas se advierte un uso y evocación constantes de figuras alusivas al mundo clásico antiguo de Grecia y Roma, que asumen un rol significante como principios productores de sentido e inteligibilidad en los discursos sobre la Guerra del Pacífico.

\section{EL ARQUETIPO DEL HÉROE ANTIGUO Y LA EXALTACIÓN DE LAS GLORIAS DE IQUIQUE}

Tras el combate naval de Iquique, los espacios de opinión pública chilenos se llenaron de elogios para Prat y sus hombres. Luego de meses de acciones erráticas, el valor y sacrificio de la tripulación de la Esmeralda ofrecieron un motivo para fortalecer la causa de la guerra y exacerbar los ánimos con-

\footnotetext{
${ }^{6}$ Las críticas a la administración de Pinto se iniciaron desde su arribo al poder y se acentuaron durante el desarrollo de la guerra, evidenciándose en una guerrilla cotidiana entre los partidos políticos y la Cámara, y en los ataques de la prensa (Mc Evoy, 2011, pp. 56-62).
} 
tra los enemigos. El hito se constituyó en el fundamento a partir del cual comenzó a codificarse un arquetipo heroico que encarnase los ideales patrios para inspirar a la población chilena, en un momento del conflicto que requería de referentes morales para proyectarse a futuro.

Las fuentes de la época evidencian un ejercicio de configuración del arquetipo heroico que, basado en una hazaña reciente, trascendió a una condición superior mediante diversas estrategias retóricas. Entre ellas, un recurso importante fue la analogía y comparación hiperbólica con gestas históricas y épicas del mundo antiguo, para inscribir el sacrificio de Prat en el relato de las grandes hazañas de la memoria occidental.

Las noticias relativas al combate provocaron reuniones públicas para compartir discursos y proclamas. El abogado y diputado por la región de Coquimbo, Pedro Nolasco, por ejemplo, leyó en Valparaíso un poema invocando a los artistas griegos clásicos, que, como modelos de autoridad, establecían la altura que merecían los elogios a los próceres del 21 de mayo:

Álcese Homero de su fosa helada Para cantar las glorias de su nombre; Vuelve a encarnarte, Fidias, en el hombre Que su gloria ha de tallar.

(Valparaíso, 1 de junio de 1879. En Ahumada, 1892, I, p. 290).

La elección de ambos personajes griegos -Homero y Fidias-, aunque distantes uno del otro en términos cronológicos, responde a su condición paradigmática como autores de las obras escritas y escultóricas que, por excelencia, definieron y representaron, en el mundo griego, el arquetipo del héroe bello y bueno, esto es, del valor de la kalokagathía. Un concepto idealizado del heroísmo, atlético y proporcionalmente equilibrado en términos corporales; arrojado y valiente en un sentido moral.

En el mismo meeting, el periodista y diputado por Los Andes, Máximo Lira, afirmaba que "los héroes de la leyenda homérica habían renacido en Iquique" (Valparaíso, 1 de junio de 1879. En Ahumada, 1892, I, p. 290), analogía similar a la ofrecida por el poeta salvadoreño, Juan Cañas ${ }^{7}$, quien aseguraba que, frente a los marinos chilenos, los héroes griegos no parecían más que pigmeos (Ahumada, 1892, I, p. 381). Los héroes homéricos o la

\footnotetext{
${ }^{7}$ Juan Cañas se encontraba desterrado en Chile y fue clave en el arribo del poeta Rubén Darío a Valparaíso.
} 
definición axiológica del héroe encarnada en ellos se asumía, así, como el criterio de medida para la valoración superlativa de la gesta chilena.

Meses después, a propósito del regreso de los marinos sobrevivientes a Valparaíso, Enrique Larraín y Zañartu, diputado por La Laja, también recurriría a la imagen del heroísmo homérico, en un discurso que recordaba el anuncio de los heraldos de Penélope al avisarle sobre el retorno de Telémaco: "Oh reina, regocíjate! Tus hijos queridos, arrancados de la metralla, a las olas, a la cantividad, acaban de tornar a tu regazo!" (15 de enero de 1880. En Ahumada, 1892, II, p. 318).

Las comparaciones no entraban en detalles, pero la recurrencia de la evocación al heroísmo homérico se confirmaba como una constante coherente con aquello que este simbolizaba. Decía Máximo Lira que no había otros casos comparables a la gesta de Iquique: "Para encontrar ejemplos de hechos análogos a estos, es preciso, señores, remontarse a los tiempos de la leyenda homérica, cuando en los combates intervenían seres superiores a los de la especie humana" (Valparaíso, 1 de junio de 1879. En Ahumada, 1892, I, p. 291).

Los personajes de la Iliada y la Odisea representaban al héroe militar clásico, que descollaba por su valentía -andreia- y cuya realización se concebía en batalla, en un agon contra el enemigo, y contra los temores y limitaciones propias; uno que alcanzaba plenitud y excelencia en la gloria -kleós- obtenida al dar la vida en defensa del honor -aidós (Caims, 1993, p. 48; Jaeger, 2006, pp. 21-22; Bauzá, 1998, p. 13). Tal caracterización del heroísmo bien podía corresponderse, sin mayores reparos, con la percepción de la élite chilena sobre la conducta de Prat y de sus hombres, lo que permitía establecer una comparación entre ambos más allá de su distancia histórica y cultural.

Después de todo, el arquetipo homérico había trascendido en el imaginario occidental a partir de fundamentos universalizables, tanto como lo hizo luego el caso histórico de los trescientos espartanos en Termópilas, durante las Guerras Médicas. La diferencia estribaba, sin embargo, en que el sacrificio de la vida de los hombres de Leónidas no se interpretaba solo como una causa en defensa del honor, sino de la polis. Por eso, su recuerdo sirvió también para elevar, por analogía, la gesta de Iquique.

En la cena de bienvenida a los marinos de la Esmeralda, el abogado y diplomático Benicio Álamos y González comparaba a los chilenos con "300 griegos [que] se inmolaban por impedir que fuese hollado el suelo de la patria" (15 de enero de 1880. En Ahumada, 1892, II, p. 318). Así atendía a ambos como si pertenecieran a una misma 'raza heroica'. Eso sería lo que 
garantizaría, tal como la trascendencia de los espartanos, la inmortalidad de los chilenos en la memoria histórica. Una editorial de El Mercurio, construyendo una metonimia, hablaba de los "Leonidas modernos", capaces de "rivalizar en heroísmo con los héroes más aclamados de la historia" ( $E l$ Mercurio, 21 de junio de 1879).

Igualmente, paralelo a las manifestaciones de Valparaíso, en Santiago, algunas personas se reunieron frente al palacio presidencial de La Moneda para expresar muestras de orgullo. Así surgió la necesidad de elevar un monumento a los héroes, tal como hacían los antiguos griegos. El diputado por Cauquenes, Macario Ossa, propuso que, así como en la Hélade existía un monumento que recordaba a los trescientos espartanos, con la inscripción "Pasajero, ve a decir a Esparta que hemos muerto aquí por obedecer sus santas leyes", en Chile debía erigirse uno con los nombres de los caídos, junto al epígrafe: "¡Así mueren los chilenos defendiendo la honra y la dignidad de su patria!" (El Mercurio, 26 de mayo de 1879).

La tradición clásica, en este sentido, no inspiraba solo discursos, sino también prácticas. Por esos mismos días, el diario El Mercurio titulaba una nota como "Una idea digna de la antigua Roma", aludiendo a una carta enviada por mujeres a Benjamín Vicuña Mackenna, ofreciendo fundir sus alhajas para condecorar a los héroes, iniciativa que, a juicio de su destinatario, emulaba perfectamente a la práctica latina (El Mercurio, 28 de mayo de 1879).

Del mismo modo, el gobierno formó comisiones para reunir recursos destinados a construir una nueva Esmeralda. La circular enviada a intendentes y gobernadores apelaba también a la autoridad de los antiguos: "El presente del rico y óbolo del pobre serán los sufragios llevados a la urna de la historia a favor de los honores del triunfo que el pueblo romano habría acordado, sin duda a Prat y a los que le secundaron" (El Mercurio, 31 de mayo de 1879).

La iniciativa se legitimaba, de este modo, por medio del recurso de autoridad que constituía el exemplum del mundo romano antiguo. Este volvía indiscutible la validez de la propuesta como una que no surgía de la creatividad individual de las autoridades chilenas, sino del modelo del pueblo latino cuyas acciones, en el imaginario moderno, se idealizaban.

El regreso de la Covadonga a Valparaíso y sus celebraciones también fueron comparados con los triunfos romanos, no solo en su realización, sino en su mérito. Una editorial de El Mercurio rememoraba, a propósito, los desfiles triunfales latinos, cuando un esclavo iba detrás del carro del vencedor, para recordar siempre la debilidad de la naturaleza humana y 
resguardar así la humildad que correspondía a un buen vencedor (El Mercurio, 24 de junio de 1879).

De esta manera, los momentos históricos se acercaban, homologándose por su cualificación, que anulaba toda distancia temporal y geográfica. La gesta del 21 de mayo merecía la elevación que Grecia y Roma habían dedicado a sus propios héroes, pues su comportamiento se igualaba más allá de las particularidades históricas. Así también lo hacía ver una carta firmada por ciudadanos porteños, dedicada al regreso del comandante Condell a Valparaíso, evocando nuevamente el contexto de las Guerras Médicas, para vincularlo, en este caso, al ejemplo ateniense: "Mucho esperábamos de nuestros marinos, ya que Chile, como la antigua Atenas, ha puesto su confianza en sus naves; pero ellos nos han dado mas de cuanto era humano exijir" (Carta de Santiago Jorge Bynon, Federico Varela y Carlos Waddington a Carlos Condell, Valparaíso, 16 de junio de 1879. En Ahumada, 1892, I, p. 361$)^{8}$.

La valoración de la fortaleza chilena inspiró, además, líneas que representaban a Chile como una tierra de hombres fuertes e invencibles. Para ello, las comparaciones con el mundo antiguo también servían. El diputado por Ancud, José Francisco Vergara, parafraseaba a un autor griego, que, aunque sin especificar, parecía referir a Esquilo y a su tragedia Los persas (239 y ss.), al señalar que la riqueza de Atenas, "ciudad de Palas" (Crónica de El Mercurio, 15 de enero de 1880. En Ahumada, 1892, II, p. 318), descansaba en el valor de sus hombres y que, tal como ella, Chile también contaba con dicha virtud, resultando así inexpugnable.

Similar caracterización realizaba el poeta Luis Rodríguez, al comparar a los héroes de Iquique con las figuras mitológicas griegas cuyo principal atributo consistía en su fuerza e indestructibilidad:

La fábula ha creado Anteos i Titanes

Que el universo entero con estupor miró...

I entre ellos i entre los altos capitanes

Igual podrá haber uno, pero más grande nó!

(Ahumada, 1892, I, p. 381)

La mención a los titanes fue recurrente, fortaleciendo la representación de los chilenos como soldados irreductibles y prácticamente sobrehumanos: como "poderoso rival de los titanes" (Ahumada, 1892, I, p. 290), había

\footnotetext{
${ }^{8}$ Las citas de fuentes del siglo XIX han respetado la ortografía original del texto.
} 
calificado Pedro Nolasco a Arturo Prat, mientras que, en su Himno a Prat, Juan Cañas reducía la talla de estos seres mitológicos a la de los pigmeos en comparación con el capitán chileno (Ahumada, 1892, I, p. 381).

Los discursos, poemas y acciones daban cuenta, de este modo, de un uso discursivo de los ejemplos épicos e históricos de la tradición clásica, con una función significante. Por medio de ellos, la representación de los hechos de Iquique se cargaba de una connotación heroica universal y suprahistórica, que los hacía dignos de inmortalización en el registro de las grandes gestas de la historia occidental. Así lo afirmaba una nota de $E l$ Mercurio, que parafraseando la locución exegi monumentum aere perennius de las Odas de Horacio (III.30.1), proclamaba la necesidad de que: "los contenporaneos del gran acontecimiento escriban en bronce o en granito la pájina histórica que mas tarde habrá de reproducirse en el libro, ese monumento mas duradero que el bronce, segun la espresion de Horacio" ( $E l$ Mercurio, 28 de mayo de 1879).

El recurso no solo embellecía los versos, sino que fortalecía su sentido, dando cuenta de un imaginario idealizado sobre el pasado grecorromano. Después de todo, este resultaba de un ejercicio de recepción por parte de los letrados chilenos, quienes, recurriendo a su bagaje cultural, resignificaban algunos pasajes clásicos del mundo antiguo, en función de su intención discursiva y del contexto que la inspiraba.

\section{EL CUESTIONAMIENTO A LA ACCIÓN DEL GOBIERNO EN LA GUERRA}

La tradición clásica no sirvió solo a las letras laudatorias. La gesta de Iquique también había despertado en la opinión pública voces críticas sobre el actuar del gobierno chileno, para las cuales los ejemplos políticos del mundo antiguo igualmente podían ser de utilidad retórica y discursiva.

Solo días después del combate naval, una editorial de El Mercurio, titulada "Lo que esperamos del Congreso", reclamaba la acción combinada de los poderes públicos y el apoyo que necesitaba el Presidente Pinto, concluyendo sobre el rol que debía inspirar al Parlamento: "Su papel es parecido al del senado romano que velaba por la quietud de la patria en el interior y su gloria en el exterior. Desempeñe, pues, ese papel augusto con la habilidad, enerjia y abnegacion que exijen las circunstancias" (El Mercurio, 31 de mayo de 1879).

No obstante, transcurridos varios días, las fuerzas militares permane- 
cían concentradas en Antofagasta, inquietando a la prensa y la opinión pública. En ese contexto, comenzaron a surgir voces más radicales. El 21 de junio de 1879, una columna firmada bajo el seudónimo de Junius y titulada La necesidad del momento es la dictadura, puso en el debate una propuesta radical: " $i$ es la plenitud de las funciones constitucionales, por parte de las corporaciones y los ciudadanos, o la DICTADURA la que hoi se necesita para la feliz y acertada direccion de la guerra?" (El Mercurio, 21 de junio de 1879).

La respuesta debía buscarse en la historia de Roma, pues en ella se hallaba el origen de esta figura gubernativa. Trascendiendo al sistema político monárquico, republicano o imperial, la dictadura era concebida por Junius como un exemplum político al que daba evidencia de conocer con detalle. Los exempla, recurso literario antiguo, se construían en base a individuos y episodios modélicos del pasado para ofrecer una lección que instruyese o conmoviese a una audiencia, ayudando a reforzar la veracidad de un argumento (Harto, 2011, pp. 509-510). Y este era el caso de la dictadura.

Desde tiempos de Tarquino, fundamentaba Junius, siendo Tito Larcio el primero, el cargo había servido en contextos de guerra, concentrando los poderes del senado y los comicios en la figura de un general, cónsul o procónsul; así había ocurrido con Camilo, Apio, Papirio, Cincinato, Diulio, Fabio, Escipión, Sila, Mario, Pompeyo y César. Grecia, afirmaba el autor, ofrecía ejemplos similares, como los de Milciades, Temístocles, Arístides, Cimón y Pericles.

La dictadura, concluía, permitiría salvar a la patria, tal como garantizaba el ejemplo histórico de las grandes civilizaciones de la Antigüedad. Y citando en latín la célebre locución ciceroniana, salus populi, suprema lex esto (De legibus III.3.8), cerraba afirmando: "La salvación del pueblo es la primera de las leyes" (El Mercurio, 21 de junio de 1879).

La editorial, quizás, era el preludio del pasquín titulado La Patria está en peligro. Su introducción es muy similar: su anónimo autor llamaba a seguir el ejemplo de griegos y romanos para resolver la inacción del gobierno chileno, asumiendo que la excelencia de los soldados chilenos podía homologarse a la de los antiguos: "¿Si hemos tenido héroes que han igualado a la gloria de Leonidas en las Termópilas, i la de Temístocles en Salamina; por qué no hallaríamos un Cincinato que salvase a la patria?" (La Patria está en peligro, 1879, p. 4).

Su intención, sin embargo, no consistía en violar la constitución. El autor proponía que el Congreso aprobase una nueva ley, de cuatro artículos, que permitiese nombrar un dictador por un año. El sistema propuesto re- 
memora de cerca el exemplum romano: al cumplirse el año, si el dictador no cesaba sus funciones, caería en la condición de tirano y cualquier ciudadano tendría el derecho de matarlo: "i el que lo hiciere será declarado por el Congreso benemérito de la patria" (La Patria está en peligro, 1879, p. 5).

La ley debería sancionarse por los dos poderes, ejecutivo y legislativo, para, finalmente, ser aprobada por un plebiscito. La propuesta evocaba así la soberanía de un senatus populusque romanus, que, mediante la votación representativa popular y la anuencia de todos los poderes del Estado, legitimaba cualquier figura política.

A ojos del autor, esta alternativa contaba con la garantía de éxito y legitimidad que el exemplum clásico ofrecía. Para ello, se apoyaba en una visión de la historia como magistra vitae, que se reforzaba luego con una metonimia que, nuevamente, acercaba el pasado a su presente como dos momentos históricos cuyo heroísmo permitía homologarlos:

¿Por qué no acudir al único recurso que nos indica la esperiencia, consignada en los anales de la historia, fiel guardadora de todas las acciones humanas? (...) ¿ cómo poner en duda de que el pais que ha producido ciudadanos como Prat i Serrano, no produciria un Marco Bruto para quebrantar la cerviz del tirano? (La Patria está en peligro, 1879, p. 7)

Los fundamentos de este discurso dan cuenta de la existencia de una comunidad cultural o de interpretación, compuesta por parte de la élite letrada y dirigente chilena, que compartía códigos comunes, forjados a través de sus experiencias educativas y lectoras. Mediante ellos, el análisis de la contingencia y el debate sobre la misma podían representarse a través de recursos argumentativos y claves históricas que reforzaban el valor del momento que estaban enfrentando. Sin duda, dicha comunidad conocía bien la historia de Roma, había aprendido a interpretarla en claves republicanas y podía recurrir a ella como elemento retórico, axiológico y político para fortalecer sus respectivas posturas.

La propuesta difundida en el pasquín, no obstante, no prosperó, y si bien la opinión pública fue crítica con el actuar del gobierno chileno en los primeros meses de la guerra, el fervor que generaron algunas batallas y gestas, como la de Prat y su tripulación, orientó la atención a los escenarios de la guerra por sobre el quehacer político. La victoria de Chile, finalmente, terminaría además por consolidar una percepción positiva de las Fuerzas Armadas y del gobierno, dejando atrás el momento de crisis que estos documentos habían denunciado. 


\section{CONCLUSIONES}

Los episodios más emblemáticos de los primeros meses de la Guerra del Pacífico inspiraron la redacción de textos de orientación pública que, sostenidamente, dieron espacio a la tradición clásica.

La revisión del marco cultural en el que los autores de dichos textos se habían formado explicaría, en parte, esta influencia: se trataba de una época de circulación y lectura frecuente de libros sobre historia antigua y los currículos académicos fomentaban una educación humanista con un fuerte componente latino. Este factor, sin embargo, no explicaría cabalmente la presencia de la tradición clásica en los textos de 1879 analizados, si no se atendiera, además, a los motivos que inspiraron su redacción. El contexto bélico, los primeros combates y divisiones políticas debieron provocar una percepción de asombro y una sensación de lo que se vivía como algo extraordinario.

Las emociones y reflexiones inspiradas bajo esas circunstancias requerían ser transcritas a partir de códigos que las revistieran de ese sentido y el ejemplo del mundo antiguo, de sus gestas épicas y modelos políticos, bien pudieron haber ofrecido un recurso discursivo para conseguirlo. No se trataba solo de una herramienta estética o retórica, sino de un recurso que, por su contenido y potencial de representación, adquiría también un rol significante, valioso para fortalecer los sentidos políticos y éticos de los discursos y textos generados en el contexto de los primeros meses de la Guerra del Pacífico.

El sacrificio de Prat y sus hombres pudo haber evocado en la imaginación de la opinión pública letrada, el recuerdo de las hazañas antiguas que habían conocido por medio de sus lecturas y formación, y la necesidad de buscar una solución política frente a la actitud del gobierno que criticaban, pudo llevar a algunos a hallarla en los sistemas que habían aprendido como modelos arquetípicos de la historia. En ambos casos, el mundo antiguo, sus exempla y sus autores más emblemáticos, al instalarse como criterios de valoración para la apreciación del momento histórico que vivía Chile, ofrecían a la élite letrada un referente de autoridad desde el cual se articulaba la opinión pública.

Un proceso de recepción cultural no consiste, en este sentido, en un ejercicio de transmisión e imitación mecánica de recursos retóricos. Este supone una práctica de lecturas, interpretación, apropiación y resignificación, que actualiza el valor del pasado para un presente en función del horizonte de intereses y expectativas de este último (Hardwick, 2003, p. 2). 
Por este motivo, la tradición clásica podía servir como argumento retórico y discursivo tanto a intenciones laudatorias como a propósitos críticos, sin caer en contradicciones.

Así se percibe en los textos de difusión pública de 1879, cuyos autores, por medio de la tradición clásica, hallaron códigos para la representación de sus percepciones e ideas, valiéndose de la voz de autoridad del mundo antiguo, que legitimaba y enaltecía el sentir de los chilenos.

\section{REFERENCIAS}

Ahumada, P. (1892). Guerra del Pacífico. Recopilación completa de todos los documentos oficiales, correspondencias $i$ demás publicaciones referentes a la guerra que ha dado a luz la prensa de Chile, Perú y Bolivia. Valparaíso, Chile: Imprenta i litografía Excelsior.

Anónimo (1879). La Patria está en peligro. Valparaíso, Chile: Imprenta del Mercurio.

Barros Arana, D. (1867). Elementos de Literatura (Retórica i Poética). Santiago, Chile: Imprenta Nacional.

Bauzá, H. (1998). El mito del héroe. Morfología y semántica de la figura heroica. Buenos Aires, Argentina: Fondo de Cultura Económica.

Briseño, R. (1965). Estadística bibliográfica de la literatura chilena: 1812-1876. Santiago, Chile: Universitaria.

Bulnes, G. (1911). Guerra del Pacífico. Santiago, Chile: Editorial del Pacífico, S.A.

Caims, D. (1993). Aidós: The Psychology and Ethics of Honour and Shame in Ancient Greek Literature. Oxford, United Kingdom: Clarendon Press.

Castagneto, P. (2015). Corresponsales en campaña de la Guerra del Pacífico. 1879-1881, Santiago, Chile: RIL.

Castillo, A. y Amelang, J. (2010). Opinión pública y espacio urbano en la Edad Moderna, Gijón, España: Trea.

Chartier, R. (1996). El orden de los libros. Lectores, autores, bibliotecas en Europa entre los siglos XIV y XVIII. Barcelona, España: Gedisa.

Cicerón, M.T. (2019). Sobre las leyes. Edición bilingüe. Buenos Aires, Argentina: Colihue Clásica.

Cruz, N. (2002). El surgimiento de la Educación Secundaria Pública en Chile, 1843-1876 (El Plan de Estudios Humanista). Santiago, Chile: Dibam.

El Mercurio, 21 de junio de 1879.

El Mercurio, 24 de junio de 1879.

El Mercurio, 28 de mayo de 1879.

El Mercurio, 31 de mayo de 1879.

Esquilo (2001). Tragedias. Madrid, España: Gredos.

Guerra, F. (2002). Voces del pueblo. Redes de comunicación y orígenes de la opinión en el mundo hispánico. Revista de Indias LXII (225), 357-384. 
Guerrero, C. (2010). Bibliografía de textos y manuales para el estudio de la historia usados en Chile en el siglo XIX. Inventario preliminar. Estudios hemisféricos y polares 2, 106-146.

Hardwick, L. (2003). Reception Studies. Oxford, United Kingdom: Oxford University Press.

Harto, M. (2011). El exemplum como figura retórica en el Renacimiento. Humanitas 63, 509-526.

Huidobro, M. (2017). Clásicos grecorromanos en tiempos de la independencia de Chile: Autores, libros e influencia. Iberoamericana XVII(64), 129-146.

Hurtado, E. (2012). Del latín al castellano o de las humanidades clásicas a las humanidades modernas en el siglo XIX chileno. Literatura y Lingüística 26, 29-46.

Idioma Latino. (1865). Anales de la Universidad de Chile t.27, 35-77. doi: 10.5354/0717-8883.2012.19617.

Jaeger, W. (2006). Paideia. Los ideales de la cultura clásica. Ciudad de México, México: Fondo de Cultura Económica.

Labarca, A. (1939). Historia de la enseñanza en Chile. Santiago, Chile: Imprenta Universitaria.

Mc Evoy, C. (2011). Guerreros civilizadores. Santiago, Chile: Ediciones Universidad Diego Portales.

Poblete, J. (2002). Literatura chilena del siglo XIX: entre públicos lectores y figuras autoriales. Santiago, Chile: Cuarto propio.

Sater, W. (2005). La imagen heroica en Chile: Arturo Prat, un santo secular. Santiago, Chile: Centro de Estudios Bicentenario.

Serrano, S. (1994). Universidad y Nación. Santiago, Chile: Universitaria.

Subercaseaux, B. (1993). Historia del libro en Chile. Santiago, Chile: Andrés Bello.

Subercaseaux, B. (1997). Historia de las ideas y de la cultura en Chile. Santiago, Chile: Universitaria.

Vial, G. (1995). Arturo Prat, Santiago, Chile: Andrés Bello.

Villalobos, A. (2008). El origen y la permanencia de los estudios griegos en Chile. Revista de Historia 18-19, 41-53.

Villalobos, A. (2017). La enseñanza de la historia universal antigua: participación y tipología de los manuales de historia en Chile republicano, 18101876. Revista de Historia Americana y Argentina LII (2), 11-40. 